\title{
GAMBARAN PENGETAHUAN IBU HAMIL TENTANG INISIASI MENYUSU DINI DI WILAYAH KERJA BPS SALSA MANDING KECAMATAN POLEWALI KABUPATEN POLEWALI MANDAR
}

\author{
Sekarwuni Manfaati
}

Latar Belakang : Pemberian ASI secara dini memberi kemungkinan delapan kali lebih besar dalam memberikan ASI eksklusif. Inisiasi menyusu dini (IMD) akan meningkatkan keberhasilan pemberian ASI ekslusif enam bulan. Kontak dini ibu dan bayi akan meningkatkan waktu menyusu menjadi dua kali lebih lama dibandingkan kontak yang lambat (Ertem,2001; Giugliani , 2004; Vaidya, K. Et al, 2005; Februhartanty, 2008). Berdasarkan studi pendahuluan di Bidan Praktek Swasta (BPS) "S" Manding Kecamatan Polewali Kabupaten Polewali Mandar pada 10 orang ibu hamil dengan metode wawancara didapatkan hasil 6 orang $(60 \%)$ dari 10 ibu hamil mempunyai pengetahuan kurang tentang IMD, 1 orang $(10 \%)$ dari10 ibu hamil mempunyai pengetahuan cukup tentang IMD dan 2 orang (20\%) dari 10 ibu hamil mengetahui tentang IMD.

Tujuan penelitian : Untuk mengetahui secara umum Gambaran Pengetahuan Ibu Hamil Tentang Inisiasi Menyusu Dini Di Wilayah Kerja BPS "S" Manding Kecamatan Polewali Kabupaten Polewali Mandar.

Metode penelitian : Penelitian ini menggunakan metode penelitian deskriptif. Populasi dalam penelitian ini adalah ibu hamil yang ada di BPS "S" Manding Kecamatan Polewali Kabupaten Polewali Mandar, periode Januari sampai Maret 2014, dimana jumlah populasi dalam penelitian ini adalah 120 orang. Sampel dalam penelitian ini adalah 55 ibu hamil yang mendukung dan bisa membaca serta menulis; penentuan jumlah sampel dalam penelitian yang digunakan adalah Simple random sampling yaitu pengambilan sampel dengan cara acak tanpa memperhatikan strata yang ada dalam dalam anggota populasi.

Hasil : rata-rata responden memiliki tingkat pengetahuan yang cukup tentang pengertian inisiasi menyusu dini yaitu sebanyak 22 orang (44\%), kriteria pengetahuan baik 23 orang (46\%) dan kriteria pengetahuan kurang 5 orang (10\%) dari 55 responden. responden memiliki pengetahuan yang kurang tentang manfaat inisiasi menyusu dini. Dimana tabel tersebut dapat dilihat bahwa ibu dengan tingkat pengetahuan cukup 14 orang (28\%), pengetahuan kurang 20 orang $(40 \%)$ dan pengetahuan baik terdapat 16 orang (32\%) dari 55 responden. Responden memiliki tingkat pengetahuan yang cukup tentang hal yang harus diperhatikan saat proses inisiasi menyusu dini yaitu sebanyak 19 responden atau (38\%), dan yang memperoleh kriteria baik sebanyak 12 responden atau (24\%).

Simpulan dan saran : Dari hasil penelitian menunjukkan bahwa peran tenaga kesehatan masih sangat diperlukan khususnya dalam memberikan pelayanan dan penyuluhan tentang inisiasi menyusu dini. Proses pendidikan hendaknya lebih memberikan wawasan dan juga ilmu yang lebih mendalam tentang inisiasi menyusu dini sehingga ilmu pengetahuan yang diperoleh peserta didik dapat diaplikasikan di masyarakat.

Kata kunci $\quad$ : ibu hamil, inisiasi menyusu dini

\section{PENDAHULUAN}

Dalam pembangunan bangsa, peningkatan kualitas manusia harus dimulai sedini mungkin sejak masih bayi. Salah satu faktor yang memegang peranan penting dalam peningkatan kualitas manusia adalah pemberian Air Susu Ibu (ASI) pada satu jam pertama. Asi merupakan sumber makanan tunggal untuk bayi 6 bulan pertama 
kehidupannya. Pemberian ASI

Ekskusif merupakan kegiatan penting dalam pemeliharaan anak dan persiapan generasi penerus yang berkualitas di masa depan. World Health Organization (WHO) melalui UNICEF pada tahun 1990 menyebutkan pemberian ASI Ekslusif selama 6 bulan, mampu mencegah 30.000 kematian bayi di Indonesia (World Health Organization).

Meskipun IMD telah diketahui banyak manfaatnya, namun pelaksanaan 'Inisiasi menyusu dini (IMD)' ternyata tidak mudah dilakukan. Dari data yang ada, hanya sekitar 14\% saja ibu melahirkan yang berhasil memberikan air susu ibunya (ASI) untuk buah hatinya. Padahal ASI sejak dini sangat bermanfaat untuk tumbuh kembang anak. Meski memiliki kandungan yang baik dan ibu sangat menjaga kandungannya sebelum melahirkan, banyak ibu yang mengeluhkan tidak keluar susu ASI usai melahirkan. Apalagi bila kondisi ibu masih stress dan tidak segera didukung oleh lingkungannya (Anik Maryunani, 2012).

Menurut penelitian Edmond, dkk yang dilakukan di Ghana pada bulan juli 2003 sampai juni 2004, yang menghubungkan antara waktu yang dilakukannya tindakan inisiasi penyusuan serta pola pemberian ASI dengan kejadian kematian bayi. Ternyata, dari 10.947 bayi yang dilahirkan dalam keadaan sehat dan diikuti perkembangannya selama sebulan, ternyata bayi yang tertunda sampai 24 jam lebih baru dilakukan kontak dengan ibunya, mengalami kematian 2,5 kali lebih banyak dibandingkan dengan bayi yang dilakukan inisiasi dini. Kesimpulannya: 22\% kematian bayi yang baru lahir, yaitu kematian yang terjadi dalam satu bulan pertama, dapat dicegah bila bayi disusui oleh ibunya dalam satu jam pertama (Anik Maryunani, 2012).

Di Indonesia saat ini tercatat angka kematian bayi masih sangat tinggi yaitu 35 tiap 1000 kelahiran hidup, itu artinya setiap hari 250 bayi meninggal, dan sekitar 175.000 bayi meninggal sebelum mencapai usia satu tahun.

Inisiasi menyusu dalam 1 jam pertama akan mengurangi kematian neonatus $22 \%$ (terlihat dari bayi mulai menyusu sendiri setelah lahir). Kontak kulit setidaknya 1 jam, sehingga $22 \%$ kematian bayi dapat diselamatkan (Anik Maryunani, 2012).

Dengan pemberian ASI dalam satu jam pertama, bayi akan mendapat zat-zat gizi yang penting dan mereka 
terlindung dari berbagai penyakit berbahaya pada masa yang paling rentan dalam kehidupannya.

Inisiasi Menyusu Dini(early initation breast freeding) atau permulaan menyusu dini adalah bayi mulai menyusu sendiri segera setelah dilahirkan. Jadi sebenarnya bayi manusia seperti bayi mamalia lainnya yang mempunyai kemampuan untuk menyusu sendiri. Asalkan dibiarkan kontak kulit bayi dengan kulit ibunya sendiri, setidaknya selama satu jam segera setelah bayi lahir. Cara melakukan inisiasi menyusu dini ini dinamakan the breast crawl atau merangkak mencari payudara (Roesli 2008).

Inisiasi menyusu dini (IMD) dapat mencegah 22\% kematian bayi di bawah usia 28 bulan di negara-negara berkembang. IMD saat bayi berusia dua hingga 24 jam pertama setelah lahir dapat mencegah $16 \%$ kematian bayi di bawah usia 28 hari (Edmond, 2006).

Pemberian ASI secara dini memberi kemungkinan delapan kali lebih besar dalam memberikan ASI eksklusif. Inisiasi menyusu dini (IMD) akan meningkatkan keberhasilan pemberian ASI ekslusif enam bulan. Kontak dini ibu dan bayi akan meningkatkan waktu menyusu menjadi dua kali lebih lama dibandingkan kontak yang lambat (Ertem,2001; Giugliani , 2004; Vaidya, K. Et al, 2005; Februhartanty, 2008).

Inisiasi menyusu dini juga berperan dalam pencapaian tujuan Millenium Development Goals (MDGs), khususnya pada tujuan keempat, yakni membantu mengurangi angka kematian bayi (Roesli, 2008).Menurut target MDGs, Indonesia saat ini tercatat angka kematian bayi masih tinggi yaitu 35/1.000 kelahiran hidup, itu artinya setiap hari bayi meninggal dan sekitar 175.000 bayi meninggal sebelum mencapai usia satu tahun. Masih banyak ibu yang belum mengerti tentang pemberian ASI Ekslusif dan pengetahuan tentang inisiasi menyusu dini. Kematian bayi baru lahir dapat dicegah jika bayi disusui oleh ibunya dalam satu jam pertama kelahirannya. Berdasarkan Survei Demografi Kesehatan Indonesia (SDKI) tercantum dalam SK Menkes No 450/MenKes/SK/IV/2004 tentang asuhan bayi baru lahir untuk satu jam pertama yang menyatakan bahwa bayi harus mendapat kontak kulit dengan kulit ibunya setelah lahir selama paling sedikit satu jam, akan tetapi pelaksanaan pemberian ASI (Air Susu Ibu) dari umur 0 bulan di Indonesia 
menurut SDKI tahun 2009 hanya $34,3 \%$ (Survey demografi Kesehatan Indonesia, 2009).

Praktek pelaksanaan IMD juga sangat bermanfaat bagi ibu hamil di masa nifas karena pada waktu bayi menghisap puting susu ibu terjadi rangsangan ke hipofisis posterior sehingga dapat dikeluarkan oksitosin yang berfungsi untuk meningkatkan kontraksi otot polos di sekitar alveoli kelenjar Air Susu Ibu (ASI) sehingga ASI dapat dikeluarkan dan terjadi rangsangan pada otot polos rahim sehingga terjadi rangsangan pada otot polos rahim sehingga terjadi percepatan involusi uterus (Yetty, 2010).

Inisiasi menyusu Dini (IMD) mampu mengembangkan insting dan refleks bayi pada satu jam setelah kelahiran. Adanya skin-to-skin contact antara ibu dan bayi mampu menstabilkan suhu badan bayi sehingga dapat terhindar dari hipotermi. Sentuhan kulit dengan kulit memberikan efek psikologis yang kuat antara ibu dan bayi. Selain itu pada satu jam pertama insting dan rangsangan bayi sangat kuat untuk menyusu kemudian menurun dan menguat lagi setelah 40 jam. Menyusu dan bukan menyusu bayi memberikan gambaran bahwa IMD bukan metode ibu menyusui bayinya tetapi bayi yang harus aktif menemukan sendiri putting susu ibu. Metode ini mempunyai manfaat yang besar untuk bayi maupun sang ibu yang baru melahirkan (Roesli,2008).

Keberhasilan atau kegagalan dalam pelaksanaan IMD dipengaruhi oleh beberapa factor antara lain adalah ibu bersalin menghadapi banyak hambatan untuk melakukan IMD terhadap bayi yang diperoleh di tempat persalinan, kurangnya dukungan yang diberikan keluarga, serta banyaknya ibu yang belum dibekali pengetahuan yang cukup tentang manfaat dari pelaksanaa IMD. Selain itu keberhasilan program Inisiasi Menyusu Dini (IMD) juga sangat dipengaruhi oleh sikap, pengetahuan, dan motivasi bidan/dokter penolong persalinan itu sendiri (Roesli,2008).

Kurangnya pengetahuan dari orang tua, pihak medis maupun keengganan untuk melakukannya membuat Inisiasi Menyusu Dini masih jarang dipraktikan. Banyak orang tua yang merasa kasihan dan tidak percaya seorang bayi yang baru lahir dapat mencari sendiri susu ibunya. Atau pun rasa malu untuk meminta dokter yang membantu persalinan untuk melakukannya (Roesli, 2008). 
Berdasarkan data yang
diperolehdi Bidan Praktek Swasta
(BPS) "S" Manding Kecamatan

Polewali Kabupaten Polewali Mandar terdapat jumlah ibu hamil pada periode Januari sampai Maret 2014 sebanyak120 orang. Berdasarkan studi pendahuluan yang dilakukan di Bidan Praktek Swasta (BPS) "S" Manding Kecamatan Polewali Kabupaten Polewali Mandar pada 10 orang ibu hamil dengan metode wawancara didapatkan hasil 6 orang (60\%) dari 10 ibu hamil mempunyai pengetahuan kurang tentang IMD, 1 orang $(10 \%)$ dari10 ibu hamil mempunyai pengetahuan cukup tentang IMD dan 2 orang (20\%) dari 10 ibu hamil mengetahui tentang IMD. Ibu hamil yang sudah pernah melakukan IMD

\section{METODE PENELITIAN}

Jenis dan Metode Penelitian

Penelitian ini menggunakan metode penelitian deskriptif yaitu suatu metode penelitian yang dilakukan dengan tujuan utama untuk membuat gambaran tentang suatu keadaan secara objektif yang digunakan untuk memecahkan atau menjawab permasalahan yang sedang dihadapi pada situasi sekarang.

\section{Lokasi dan Waktu Penelitian}

mengatakan bahwa bayinya sehat dan ibu hamil tidak mengalami bendungan ASI. Ibu hamil yang tidak pernah melakukan IMD mengatakan bahwa bayinya mudah terkena penyakit karena daya tahan tubuh berkurang dan ibu hamil yang tidak pernah melakukan IMD akan terjadi bendungan ASI pada hari pertama setelah ibu melahirkan.

Berdasarkan uraian diatas maka peneliti tertarik untuk melakukan penelitian yang dituangkan dalam Usulan Penelitian ini dengan judul "Gambaran Pengetahuan Ibu Hamil Tentang Inisiasi Menyusu Dini (IMD) Di Wilayah Kerja BPS Salsa Manding Kecamatan Polewali Kabupaten Polewali Mandar"

Pengambilan data dilaksanakan pada bulan Januari-Maret 2014 sampai batas waktu yang telah ditentukan, tempat penelitian dilakukan di BPS "S" Manding Kecamatan Polewali Kabupaten Polewali Mandar Populasi dan Sampel Populasi

Populasi dalam penelitian ini adalah ibu hamil yang ada di BPS "S" Manding Kecamatan Polewali Kabupaten Polewali Mandar, periode Januari sampai Maret 2014, dimana jumlah populasi dalam penelitian ini adalah 120 orang.

Sampel

Sampel dalam penelitian ini adalah 55 ibu hamil yang mendukung dan bisa membaca serta menulis; 
penentuan jumlah sampel dalam penelitian yang digunakan adalah Simple random sampling yaitu pengambilan sampel dengan cara acak tanpa memperhatikan strata yang ada dalam dalam anggota populasi.

HASIL DAN PEMBAHASAN

Hasil Penelitian

Tabel 4.1

Distribusi Frekuensi Responden Berdasarkan Karakteristik Umur di BPS "S" Manding Kecamatan Polewali Kabupaten Polewali Mandar Tahun 2015

\begin{tabular}{|c|c|c|c|}
\hline No & Umur Responden & Frekuensi & Persentase (\%) \\
\hline 1 & $<20$ & 5 & $09,09 \%$ \\
\hline 2 & \multirow[b]{2}{*}{$20-35$} & 45 & $81,82 \%$ \\
\hline 3 & & \multirow{2}{*}{5} & \multirow{2}{*}{$09,09 \%$} \\
\hline & $>35$ & & \\
\hline & Total & 55 & 100 \\
\hline
\end{tabular}

Sumber : Data Primer

Berdasarkan umur

responden, di dapatkan

presentase terbesar adalah

mereka yang berumur 20-35

$(81,82 \%)$, umur $<20$ sebanyak

tahun yaitu sebanyak 45 orang

5 orang $(09,09 \%)$, dan umur >

35 tahun sebanyak 5 orang $(09,09 \%)$

Tabel 4.2

Distribusi Responden Berdasarkan Pendidikan di BPS "S" Manding Kecamatan Polewali Kabupaten Polewali Mandar Tahun 2015

\begin{tabular}{|c|c|c|c|}
\hline No & Pendidikan & Frekuensi & Persentase (\%) \\
\hline 1 & SD & 11 & $20,00 \%$ \\
2 & SMP & 21 & $38,18 \%$ \\
3 & SMA & 23 & $41,82 \%$ \\
4 & AK & 0 & $0 \%$ \\
5 & PT & 0 & $0 \%$ \\
\hline & Total & $\mathbf{5 5}$ & $\mathbf{1 0 0}$ \\
\hline
\end{tabular}

Sumber : Data Primer

Dari tabel diatas dapat

21 orang $(38,18 \%), \quad S D$

dilihat bahwa sebagian

sebanyak $11 \quad$ orang besar responden

berpendidikan SMA

(20,00\%), AK (Akademi)

sebanyak 23 orang sebanyak 0 responden atau (41,82\%), SMP sebanyak 
Tinggi) sebanyak $\quad 0$

responden atau $(0 \%)$.

Tabel 4.3

Distribusi Responden Berdasarkan Pekerjaan Di BPS " $S$ " Manding Kecamatan Polewali Kabupaten Polewali Mandar Tahun 2015

\begin{tabular}{|c|c|c|c|}
\hline No & Pekerjaan & Frekuensi & Persentase (\%) \\
\hline 1 & Pegawai Negeri Sipil & 0 & $0 \%$ \\
2 & Wiraswasta & 18 & $32,73 \%$ \\
3 & Ibu Rumah Tangga & 37 & $67,27 \%$ \\
\hline \multicolumn{2}{|c|}{ Jumlah } & $\mathbf{5 5}$ & $\mathbf{1 0 0}$ \\
\hline
\end{tabular}

Sumber : Data Primer

Tabel diatas menunjukkan

bahwa sebagian besar

responden mempunyai

$(67,27 \%)$, wiraswasta ada 18

pekerjaan sebagai ibu rumah orang $(32,73 \%)$, dan yang bekerja sebagai PNS sebanyak tangga sebanyak 37 orang 0 responden atau $(0 \%)$.

\section{Variabel yang Diteliti}

Tabel 4.4

Distribusi Frekuensi Tingkat Pengetahuan Ibu Hamil Tentang Pengertian Inisiasi Menyusu Dini Di BPS “S' Manding Kecamatan Polewali Kabupaten Polewali Mandar Tahun 2015

\begin{tabular}{|l|c|c|c|}
\hline No & Kategori & Frekuensi & Persentase (\%) \\
\hline 1 & Baik & 23 & $46 \%$ \\
2 & Cukup & 22 & $44 \%$ \\
3 & Kurang & 5 & $10 \%$ \\
\hline \multicolumn{2}{|c|}{ Jumlah } & $\mathbf{5 0}$ & $\mathbf{1 0 0}$ \\
\hline
\end{tabular}

Sumber : Data Primer

Tabel tersebut

22 orang (44\%), kriteria

menunjukkan bahwa rata-rata pengetahuan baik 23 orang responden memiliki tingkat (46\%) dan kriteria pengetahuan pengetahuan yang cukup kurang 5 orang $(10 \%)$ dari 55 tentang pengertian inisiasi responden.

menyusu dini yaitu sebanyak

Tabel 4.5

Distribusi Frekuensi Tingkat Pengetahuan Ibu Hamil tentang Manfaat Inisiasi Menyusu Dini Di BPS "S" Manding Kecamatan Polewali Kabupaten Polewali Mandar Tahun 2015

\begin{tabular}{|c|c|c|c|}
\hline No & Kategori & Frekuensi & $\begin{array}{c}\text { Persentase } \\
(\boldsymbol{\%})\end{array}$ \\
\hline 1 & Baik & 16 & $32 \%$ \\
2 & Cukup & 14 & $28 \%$ \\
3 & Kurang & 20 & $40 \%$ \\
\cline { 3 - 4 } & &
\end{tabular}




\begin{tabular}{|c|c|c|}
\hline Jumlah & $\mathbf{5 0}$ & $\mathbf{1 0 0}$ \\
\hline Sumber : Data Primer
\end{tabular}

$\begin{array}{lrrl}\text { Tabel } & \text { tersebut } & \text { dengan tingkat pengetahuan } \\ \text { enunjukkan bahwa } & \text { rata-rata } & \text { cukup } 14 \text { orang (28\%), } \\ \text { sponden } & \text { memiliki } & \text { pengetahuan kurang 20 orang } \\ \text { pengetahuan yang } & \text { kurang } & (40 \%) \text { dan pengetahuan baik } \\ \text { ntang manfaat inisiasi } & \text { terdapat 16 orang (32\%) dari 55 } \\ \text { menyusu dini. Dimana tabel } & \text { responden. }\end{array}$

tersebut dapat dilihat bahwa ibu

Tabel 4.6

Distribusi Frekuensi Tingkat Pengetahuan Ibu Hamil tentang Tahapan Perilaku Bayi Dalam Proses Inisiasi Menyusu Dini Di BPS “S” Manding Kecamatan Polewali Kabupaten Polewali Mandar Tahun 2015

\begin{tabular}{|c|c|c|c|}
\hline No & Kategori & Frekuensi & Persentase (\%) \\
\hline 1 & Baik & 12 & $24 \%$ \\
\hline 2 & Cukup & 19 & $38 \%$ \\
\hline 3 & Kurang & 19 & $38 \%$ \\
\hline & Jumlah & 50 & 100 \\
\hline
\end{tabular}

Sumber : Data Primer

Tabel diatas menunjukkan bahwa rata-rata responden memiliki tingkat pengetahuan bayi dalam proses inisiasi menyusu dini yaitu sebanyak cukup tentang tahapan perilaku

19 orang.

Tabel 4.7

Distribusi Frekuensi Tingkat Pengetahuan Ibu Hamil tentang Hal Yang Harus Diperhatikan Saat Proses Inisiasi Menyusu Dini Di BPS “ S” Manding Kecamatan Polewali Kabupaten Polewali Mandar Tahun 2015

\begin{tabular}{|c|c|c|c|}
\hline No & Kategori & Frekuensi & Persentase (\%) \\
\hline 1 & Baik & 12 & $24 \%$ \\
\hline 2 & Cukup & 19 & $38 \%$ \\
\hline 3 & Kurang & 19 & $38 \%$ \\
\hline & Jumlah & 50 & 100 \\
\hline
\end{tabular}

Sumber : Data Primer

Tabel tesebut menunjukkan

bahwa rata-rata responden memiliki tingkat pengetahuan yang cukup tentang hal yang harus diperhatikan saat proses

inisiasi menyusu dini yaitu sebanyak 19 responden atau (38\%), dan yang memperoleh kriteria baik sebanyak 12 responden atau (24\%). 
1. Tingkat Pengetahuan Responden Tentang Pengertian Inisiasi Menyusu Dini

Hasil penelitian tingkat pengetahuan tentang pengertian imunisasi Tetanus Toxoid berdasarkan tabel 4.6 menunjukkan bahwa dari 50 responden yang memperoleh kriteria baik sebanyak 23 responden atau (46,00\%), yang memperoleh kriteria cukup 22 sebanyak responden atau $(44,00 \%)$, dan yang mempunyai kriteria kurang sebanyak 5 responden atau $(10,00 \%)$.

Sebagian besar responden cukup bisa memahami tentang pengertian imunisasi Tetanus Toxoid dikutip oleh (Nina Siti Mulyani, SST dkk, 2013 : 38). Hal ini dapat dilihat dari latar belakang pendidikan yaitu SD, SMP dan SMA disamping itu juga Ibu Hamil yang tidak pernah mendapat informasi ataupun pemahaman mengenai imunisasi Khusunya Imunisasi Tetanus Toxoid. Hal ini dapat dilihat dari jawaban yang salah tentang pengertian imunisasi Tetanus Toxoid. Hal ini dapat dilatarbelakangi pendidikan yang tidak pernah mendapatkan informasi tentang pengertian imunisasi Tetanus Toxoid dari manapun. Hal ini diperkuat oleh Notoatmodjo (2005) bahwa pengalaman merupakan sumber pengetahuan.

Berdasarkan penelitian yang telah dilakukan dapat ditarik simpulan bahwa pengetahuan Ibu hamil Tentang Pengertian Imunisasi Tetanus Toxoid Tahun 2014 berada pada kategori cukup.

2. Tingkat Pengetahuan Ibu Hamil Tentang Manfaat Imunisasi Tetanus Toxoid

Hasil penelitian tingkat pengetahuan Ibu Hamil tentang Manfaat Imunisasi Tetanus Toxoid tabel 4.5 menunjukkan bahwa dari 50 responden yang memperoleh kriteria baik sebanyak 16 responden atau (32,00\%), yang memperoleh kriteria cukup sebanyak 14 responden atau $(28,00$ $\%)$, dan yang mempunyai kriteria kurang sebanyak 20 responden atau $(40,00 \%)$.

Pencapaian pengetahuan cukup hal ini disebabkan pendidikan yang rendah dan dilihat dari pekerjaan ibu hamil sebagian besar sebagai ibu rumah tangga dimana mereka masih membutuhkan pengetahuan dan pemahaman tentang manfaat Imunisasi Tetanus Toxoid. Hal ini 
diperkuat oleh Notoatmodjo (2003)

bahwa pengalaman merupakan guru yang baik untuk memperoleh pengetahuan.

Berdasarkan penelitian yang telah dilakukan dapat ditarik simpulan bahwa pengetahuan ibu hamil tentang manfaat Imunisasi Tetanus Toxoid, berada pada kategori cukup.

3. Dampak yang terjadi jika tidak imunisasi TT

Dampak yang terjadi jika ibu hamil tidak imunisasi TT yaitu tidak memiliki perlindungan dari infeksi tetanus dan juga tidak melindungi bayi/janin dari tetanus yang sering dikenal dengan tetanus neonatorum (Deswita:2009)

Hasil penelitian tingkat pengetahuan Ibu Hamil tentang Manfaat Imunisasi Tetanus Toxoid tabel 4.5 menunjukkan bahwa dari 50 responden yang memperoleh kriteria baik sebanyak 12 responden atau $(24,00 \%)$, yang memperoleh kriteria cukup sebanyak 19 responden atau $(38,00$ $\%$ ), dan yang mempunyai kriteria kurang sebanyak 19 responden atau $(38,00 \%)$.

\footnotetext{
Pencapaian pengetahuan cukup hal ini disebabkan pendidikan yang rendah dan dilihat
}

dari pekerjaan ibu hamil sebagian besar sebagai ibu rumah tangga dimana mereka masih membutuhkan pengetahuan dan pemahaman tentang manfaat Imunisasi Tetanus Toxoid. Hal ini diperkuat oleh Notoatmodjo (2003) bahwa pengalaman merupakan guru yang baik untuk memperoleh pengetahuan.

Berdasarkan penelitian yang telah dilakukan dapat ditarik simpulan bahwa pengetahuan ibu hamil tentang dampak yang terjadi jika tidak Imunisasi Tetanus Toxoid, berada pada kategori cukup.

4. Tingkat Pengetahuan Ibu Hamil Tentang Waktu Pemberian Imunisasi TT

Hasil penelitian tingkat pengetahuan tentang waktu Pemberian Imunisasi Tetanus Toxoid tabel 4.6 menunjukkan bahwa dari 50 responden yang memperoleh kriteria baik sebanyak 22 responden atau $(44,00 \%)$, yang memperoleh kriteria cukup sebanyak 16 responden atau $(32,00 \%)$, dan yang mempunyai kriteria kurang sebanyak 12 responden atau $(24,00 \%)$.

$$
\text { Berdasarkan penelitian }
$$
yang telah dilakukan dapat ditarik 
kesimpulan bahwa pengetahuan Ibu Hamil tentang jadwal Pemberian Imunisasi Tetanus Toxoid di BPS Sayang Ibu"U" kategori Cukup. Yang dikarenakan sebagian besar responden rata-rata hanya berpendidikan sekolah Dasar. Dimana dengan rendahnya tingkat pendidikan sesorang maka kemampuan untuk menerima pesan yang diberikan akan sulit. Sehingga responden akan sulit untuk menerima hal-hal baru termasuk hal yang berkaitan Imunisasi Tetanus Toxoid.

\section{KESIMPULAN DAN SARAN}

\section{Kesimpulan}

Dari penelitian yang telah dilakukan terhadap 55 responden dengan tingkat pengetahuan ibu hamil tentang Inisiasi Menyusu Dini di wilayah kerja BPS "S" manding kecamatan polewali kabupaten polewali mandar dapat diperoleh kesimpulan sebagai berikut:

1. Tingkat pengetahuan ibu hamil tentang pengertian inisiasi menyusu dini yang berada pada kategori cukup yaitu 37 responden $(44 \%)$.

2. Tingkat pengetahuan Ibu hamil tentang manfaat inisiasi menyusu dini yang berada pada kategori cukup yaitu 27 responden (28\%).

3. Tingkat pengetahuan Ibu hamil tentang tahapan perilaku bayi dalam proses inisiasi menyusu dini yang berada pada kategori cukup yaitu 27 responden (38\%).

4. Tingkat pengetahuan ibu Hamil tentang hal yang harus diperhatikan saat inisiasi menyusu dini yang berada pada kategori cukup yaitu 13 responden $(32 \%)$.

\section{DAFTAR PUSTAKA}

Aprilia, Y. (2010). Hipnostetri. Jakarta: bagas media

Arikunto, S (2006). Prosedur Penelitian Suatu Pendekatan Praktek. Jakarta : Rineka Cipta.

Hidayat, A.L. (2007). Metode Penelitian Kebidanan Dan Teknik Analisa Data .Jakarta: salemba medika

Marmi, (2011). Asuhan Kebidanan Pada Masa Antenatal, PT Pustaka Belajar, Yogyakarta

Maryunani, A. (2012). Inisiasi Menyusu Dini, Asi Esklusif, Cara Manajemen Laktasi. Jakarta: TIM.

Notoatmodjo, S. (2007).Kesehatan Masyarakat Ilmu dan Seni. Jakarta: Rineka Cipta. 
Notoatmodjo.S. (2010). Metodologi

Penelitian Kesehatan. Jakarta:

Rineka Cipta.

Saifuddin, A, B. (2009). Buku Acuan

Nasional Pelayanan Kesehatan

Maternal dan Neonatal, PT Bina

Pustaka Sarwono Prawirohardjo,

Jakarta

Saryono.(2011). Metode Penelitian

Kesehatan.Yogyakarta: Mitra

Cendekia Press.

Sekolah Tinggi Ilmu Kesehatan Bina Generasi Polewali (2014). Pedoman Penyusunan dan Penulisan Karya Tulis Ilmiah dan Skripsi. Polewali

Sutomo, dkk. (2010). Makanan Sehat Pendamping ASI. Jakarta: Demedia Pustaka

Wawan, dkk. (2011). Pengetahun, Sikap, Dan Perilaku Manusia. Yokyakarta: Nuha Medika.

Winkjosastro, H. (2005). Ilmu kebidanan. Yayasan Bina Pustaka sarwono prawirohardjo, Jakarta.

Zaman, dkk (2010). Nama Indah Pembawa Berkah Untuk Buah Hati. Jakarta: Trans Media Pustaka. 